\title{
ORIGINAL ARTICLE Blood pressure changes after renal denervation at 10 European expert centers
}

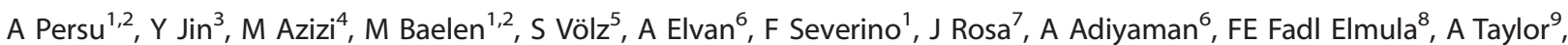 \\ A Pechère-Bertschi ${ }^{10}, \mathrm{G}$ Wuerzner ${ }^{11}, \mathrm{~F}$ Jokhaji ${ }^{12}, \mathrm{~T} \mathrm{Kahan}^{12}$, J Renkin ${ }^{1}, \mathrm{M}$ Monge ${ }^{4}, \mathrm{P}$ Widimský ${ }^{7}, \mathrm{~L}$ Jacobs $^{3}, \mathrm{M} \mathrm{Burnier}^{11}$, \\ PB Mark ${ }^{9}$, SE Kjeldsen ${ }^{8}$, B Andersson ${ }^{5}$, M Sapoval ${ }^{4}$ and JA Staessen ${ }^{3,13}$ on behalf of the European Network COordinating research \\ on Renal Denervation (ENCOReD) ${ }^{14}$
}

We did a subject-level meta-analysis of the changes $(\Delta)$ in blood pressure (BP) observed 3 and 6 months after renal denervation (RDN) at 10 European centers. Recruited patients ( $n=109 ; 46.8 \%$ women; mean age 58.2 years) had essential hypertension confirmed by ambulatory BP. From baseline to 6 months, treatment score declined slightly from 4.7 to 4.4 drugs per day. Systolic/ diastolic BP fell by $17.6 / 7.1 \mathrm{~mm} \mathrm{Hg}$ for office BP, and by $5.9 / 3.5,6.2 / 3.4$, and $4.4 / 2.5 \mathrm{~mm} \mathrm{Hg}$ for $24-\mathrm{h}$, daytime and nighttime BP $(P \leqslant 0.03$ for all). In 47 patients with 3- and 6-month ambulatory measurements, systolic BP did not change between these two time points $(P \geqslant 0.08)$. Normalization was a systolic BP of $<140 \mathrm{~mm} \mathrm{Hg}$ on office measurement or $<130 \mathrm{~mm} \mathrm{Hg}$ on $24-\mathrm{h}$ monitoring and improvement was a fall of $\geqslant 10 \mathrm{~mm} \mathrm{Hg}$, irrespective of measurement technique. For office BP, at 6 months, normalization, improvement or no decrease occurred in 22.9, 59.6 and 22.9\% of patients, respectively; for 24-h BP, these proportions were 14.7, 31.2 and 34.9\%, respectively. Higher baseline BP predicted greater BP fall at follow-up; higher baseline serum creatinine was associated with lower probability of improvement of $24-\mathrm{h} \mathrm{BP}$ (odds ratio for $20-\mu \mathrm{moll} \mathrm{I}^{-1}$ increase, $0.60 ; P=0.05$ ) and higher probability of experiencing no $\mathrm{BP}$ decrease $(\mathrm{OR}, 1.66 ; P=0.01)$. In conclusion, $\mathrm{BP}$ responses to RDN include regression-to-the-mean and remain to be consolidated in randomized trials based on ambulatory BP monitoring. For now, RDN should remain the last resort in patients in whom all other ways to control BP failed, and it must be cautiously used in patients with renal impairment.

Journal of Human Hypertension (2014) 28, 150-156; doi:10.1038/jhh.2013.88; published online 26 September 2013

Keywords: ambulatory blood pressure measurement; renal denervation; resistant hypertension; white-coat effect

\section{INTRODUCTION}

Depending on populations studied and applied methods and definitions, the prevalence of treatment-resistant hypertension varies from $10-15 \%{ }^{1}$ The SYMPLICITY studies ${ }^{2-4}$ demonstrated that in this indication catheter-based endovascular sympathetic renal denervation (RDN) by means of low-frequency energy is feasible. It entails a $25-30 \mathrm{~mm} \mathrm{Hg}$ decrease in office systolic blood pressure (BP), $84 \%$ of patients achieving a decrease in office systolic BP of $10 \mathrm{~mm} \mathrm{Hg}$ or more with a rate of procedural adverse events lower than $5 \% .^{3}$ However, as reviewed elsewhere, ${ }^{5,6}$ the SYMPLICITY reports and subsequent studies ${ }^{7}$ did not yet generate conclusive evidence. The post-procedural changes in the ambulatory BP, regrettably reported in few studies, did not always reach statistical significance. ${ }^{7}$ Finally, the nonrandomized open design of most RDN studies and publication bias limit the inferences that can be made from published data. ${ }^{7,8}$

To address these concerns, we performed a subject-level meta-analysis of the responses of the office and ambulatory BP
6 months after RDN at 10 expert centers involved in the European Network COordinating research on Renal Denervation (ENCOReD). In addition, we compared our current findings with those observed in the SYMPLICITY HTN-2 trial $^{3}$ and in elderly patients with isolated systolic hypertension, ${ }^{9}$ another difficult-tocontrol hypertension subtype. ${ }^{1,10,11}$

\section{SUBJECTS AND METHODS}

Patients undergoing RDN

We carried out systematic reviews of the literature published elsewhere, ${ }^{6,7}$ and identified ENCOReD centers engaging in RDN. Patients being followed up in the framework of still ongoing investigator-initiated or industry-sponsored trials or observational studies awaiting independent publication could not be included. Following the 4th ENCOReD network meeting, held in Leuven on 26 April 2013, 10 centers with patients available according to the foregoing criterion volunteered to contribute data to this patient-level meta-analysis. Participating centers provided information on 166 consecutively enrolled patients who underwent RDN because of resistant hypertension. Of those, we

${ }^{1}$ Pole of Cardiovascular Research, Institut de Recherche Expérimentale et Clinique, Université Catholique de Louvain, Brussels, Belgium; ${ }^{2}$ Division of Cardiology, Cliniques Universitaires Saint-Luc, Université Catholique de Louvain, Brussels, Belgium; ${ }^{3}$ Studies Coordinating Centre, Research Unit Hypertension and Cardiovascular Epidemiology, KU Leuven Department of Cardiovascular Sciences, University of Leuven, Leuven, Belgium; ${ }^{4}$ Faculté de Médecine, Université Paris Descartes, Paris, France; ${ }^{5}$ Department of Cardiology, Sahlgrenska University Hospital, Gothenburg, Sweden; ${ }^{6}$ Department of Cardiology, Isala Klinieken, Zwolle, The Netherlands; ${ }^{7}$ Third Department of Internal Medicine, General Faculty Hospital, Prague, Czech Republic; ${ }^{8}$ Department of Cardiology, Ullevål University Hospital, University of Oslo, Oslo, Norway; ${ }^{9}$ BHF Glasgow Cardiovascular Research Centre, University of Glasgow, Glasgow, UK; ${ }^{10}$ Hypertension Unit, Geneva University Hospital, Geneva, Switzerland; ${ }^{11}$ Service of Nephrology, Lausanne University Hospital, Lausanne, Switzerland; ${ }^{12}$ Division of Cardiovascular Medicine, Department of Clinical Sciences, Danderyd Hospital, Karolinska Institute, Stockholm, Sweden and ${ }^{13}$ Department of Epidemiology, Maastricht University, Maastricht, The Netherlands. Correspondence: Professor JA Staessen, Studies Coordinating Centre, Research Unit Hypertension and Cardiovascular Epidemiology, KU Leuven Department of Cardiovascular Sciences, University of Leuven, Kapucijnenvoer 35, Block D, Box 7001, BE-3000 Leuven, Belgium.

E-mail: jan.staessen@med.kuleuven.be or ja.staessen@maastrichtuniversity.nl

${ }^{14}$ Contributing ENCOReD centers are listed in the online Supplementary Data.

Received 28 June 2013; revised 5 August 2013; accepted 9 August 2013; published online 26 September 2013 
excluded 57 because they did not have their ambulatory BP measured either at baseline or at 6 months of follow-up. The number of patients eligible for inclusion in the current analysis therefore totaled 109, of whom 47 had an intermediary assessment of their BP at 3 months.

The eligibility criteria for RDN at the participating centers complied with European consensus ${ }^{12}$ and included: (i) optimized and stable treatment for at least 6 weeks with three or more antihypertensive drug classes at the maximal-tolerated dose, preferably including a diuretic (all 10 centers), or intolerance to all antihypertensive drugs (two patients in one center); (ii) a systolic BP on office measurement of at least $140 \mathrm{~mm} \mathrm{Hg}$ (five centers) or $160 \mathrm{~mm} \mathrm{Hg}(150 \mathrm{~mm} \mathrm{Hg}$ in diabetic patients; two centers), a daytime or 24-h systolic BP of at least 135 or $130 \mathrm{~mm} \mathrm{Hg}$, respectively (eight centers); (iii) an estimated glomerular filtration rate (eGFR) ${ }^{13}$ of $30 \mathrm{ml} \mathrm{min}^{-1}$ per $1.73 \mathrm{~m}^{2}$ or higher; (iv) systematic exclusion of secondary hypertension; (v) suitable anatomy of the renal arteries ${ }^{2,3}$ (vi) and approval by each center's Institutional Review Board and signed informed consent. As in SYMPLICITY HTN $-2^{3}$ and in line with current European ${ }^{12}$ and French ${ }^{14}$ guidelines nonsignificant $(<50 \%)$ lesions of the renal arteries were not an exclusion criterion. The RDN systems used included Symplicity Catheter System (Ardian, Mountain View, CA, USA) in $98(89.9 \%)$ patients and other catheters in $11(10.1 \%)$.

\section{Reference groups}

The first reference group consisted of patients with resistant hypertension, who were randomized in the SYMPLICITY HTN-2 trial and completed the 6 -month follow-up either on usual therapy $(n=51)$ or after RDN $(n=49){ }^{3}$ The second reference group included 152 patients, who were randomized in the Systolic Hypertension in Europe trial (Syst-Eur) and who had their ambulatory BP measured twice during the 3 -month run-in period, ${ }^{15}$ while on single-blind placebo treatment and 6 months after randomization on treatment with either placebo $(n=73)$ or active drugs $(n=79)$. A more detailed description of the reference groups is available in the study by Esler et al. ${ }^{3}$ for SYMPLICITY HTN-2 and in the study by Staessen et al..$^{9}$ and in the online-only Expanded Methods for Syst-Eur.

\section{BP measurement}

In the RDN studies and in the Syst-Eur trial contemporary guidelines for the measurement of BP were applied. ${ }^{16-18}$ In the current RDN studies, office BP was measured either by auscultation of the Korotkoff sounds (one center) or by validated oscillometric devices (nine centers). The number of office readings averaged per visit ranged from two to five. All participating centers used validated portable monitors to measure the ambulatory BP according to the guidelines of the European Society of Hypertension. ${ }^{18}$ Daytime and nighttime were defined using diaries and long fixed-time clock intervals. ${ }^{19}$ Across centers, the intervals between daytime and nighttime readings ranged from 15 to $30 \mathrm{~min}$ and from 20 to $60 \mathrm{~min}$, respectively. The white-coat effect was office minus 24 -h or daytime BP.

\section{Statistical methods}

We used SAS, version 9.3, for database management and statistical analysis. We applied $t$-tests to compare unadjusted means and to determine the significance of unadjusted within-group BP changes (follow-up measurement subtracted from baseline) and the $\chi^{2}$-statistic to compare proportions. To compute significance of BP changes, while adjusting for baseline and accounting for center or study as a random effect, we applied a generalization of the standard linear model, as implemented in the PROC MIXED procedure of SAS package. In multivariable-adjusted analyses, we considered sex, age, body mass index, serum creatinine and a history of diabetes mellitus or cardiovascular disease as potential predictors of the BP responses. We also applied multivariable-adjusted logistic regression to identify predictors of BP status at 6 months of follow-up. As in the SYMPLICITY studies, ${ }^{2-4}$ reaching systolic BP control was defined by achieving levels below $140 \mathrm{~mm} \mathrm{Hg}$ on office or below $130 \mathrm{~mm} \mathrm{Hg}$ on 24-h ambulatory measurement, respectively. Improvement was defined as a decrease in the office or 24-h systolic BP by at least $10 \mathrm{~mm} \mathrm{Hg}{ }^{2,3}$ No decrease in BP was defined as a systolic BP at 6 months equal to or higher than the baseline value. Significance was defined as a $P$ value of 0.05 or less.

\section{RESULTS}

Baseline characteristics

Table 1 lists the baseline characteristics of the patients who underwent RDN by level of office systolic BP before RDN.
Table 1. Characteristics of 109 patients by level of office systolic pressure

\begin{tabular}{|c|c|c|c|}
\hline \multirow{2}{*}{$\begin{array}{l}\text { Baseline } \\
\text { characteristic }\end{array}$} & \multicolumn{3}{|c|}{ Office systolic blood pressure } \\
\hline & $<160 \mathrm{~mm} \mathrm{Hg}$ & $160-179 \mathrm{~mm} \mathrm{Hg}$ & $\geqslant 180 \mathrm{~mm} \mathrm{Hg}$ \\
\hline Number of patients & 35 & 33 & 41 \\
\hline \multicolumn{4}{|c|}{ Number (\%) with characteristic } \\
\hline $\begin{array}{l}\text { Non-white } \\
\text { ethnicity }\end{array}$ & $2(5.7)$ & $0(0)$ & $2(4.9)$ \\
\hline Women & $10(28.6)$ & $11(33.3)$ & $30(73.2) \ddagger$ \\
\hline Diabetes mellitus & $9(25.7)$ & $11(33.3)$ & $8(19.5)$ \\
\hline \multicolumn{4}{|c|}{ Previous cardiovascular disease } \\
\hline $\begin{array}{l}\text { Coronary heart } \\
\text { disease }\end{array}$ & $7(20.0)$ & $10(30.3)$ & $8(19.5)$ \\
\hline Stroke & $4(11.4)$ & $3(9.1)$ & $2(4.9)$ \\
\hline \multicolumn{4}{|c|}{ Mean (s.d.) characteristic } \\
\hline Age, years & $57.6 \pm 10.8$ & $60.3 \pm 11.1$ & $57.1 \pm 11.8$ \\
\hline $\begin{array}{l}\text { Body mass index, } \\
\mathrm{kg} \mathrm{m}^{-2}\end{array}$ & $28.1 \pm 4.2$ & $30.6 \pm 4.5^{*}$ & $29.7 \pm 5.2$ \\
\hline $\begin{array}{l}\text { Serum creatinine, } \\
\left.\mu \mathrm{mol}\right|^{-1}\end{array}$ & $92.8 \pm 30.8$ & $92.6 \pm 23.2$ & $72.0 \pm 19.7 \ddagger$ \\
\hline $\begin{array}{l}\text { eGFR, } \mathrm{ml} \mathrm{min}^{-1} \\
\text { per } 1.73 \mathrm{~m}^{-2}\end{array}$ & $76.5 \pm 21.9$ & $77.5 \pm 22.9$ & $90.9 \pm 27.1^{*}$ \\
\hline
\end{tabular}

eGFR indicates the glomerular filtration rate estimated from the serum creatinine concentration. ${ }^{13}$ Significance of the difference with the left adjacent column: $* P \leqslant 0.05 ; \uparrow P \leqslant 0.001$

Supplementary Table S1, available in the online-only Data Supplement, provides the same baseline characteristics by center. Of the 109 RDN patients, 23 (21.1\%) had isolated systolic hypertension, $12(11.0 \%)$ had taken part in the SYMPLICITY HTN2 trial $^{3}$ and 4 (3.7\%) had an office systolic BP of $<140 \mathrm{~mm} \mathrm{Hg}$ but a 24-h systolic BP higher than $137 \mathrm{~mm} \mathrm{Hg}$. Supplementary Table S2 lists systolic BP at baseline by center.

\section{Unadjusted analyses of the responses to RDN}

In 97 (88.9\%) patients with information available in our data set, the number of drug classes taken decreased from $4.7 \pm 1.5$ (s.d.) at baseline to $4.4 \pm 1.7$ at 6 months $(P=0.001)$. All BP reductions at 6 months were significant $(P \leqslant 0.030$; Table 2$)$. The systolic/diastolic reductions averaged $17.6 / 7.1 \mathrm{~mm} \mathrm{Hg}$ for office $B P$, and $5.9 / 3.5 \mathrm{~mm} \mathrm{Hg}$, $6.2 / 3.4 \mathrm{~mm} \mathrm{Hg}$ and $4.4 / 2.5 \mathrm{~mm} \mathrm{Hg}$ for the 24-h, daytime and nighttime BP values, respectively. From baseline to 6 months of follow-up, the systolic/diastolic white-coat effect, as assessed by 24-h ambulatory or daytime BP monitoring, decreased $(P<0.001)$ by $12.0 / 3.7 \mathrm{~mm} \mathrm{Hg}$ and by $11.8 / 3.7 \mathrm{~mm} \mathrm{Hg}$, respectively. Figure 1 shows that in 47 patients with measurements available at 3 and 6 month, office and 24-h systolic BP levels were similar at these two time points $(P \geqslant 0.080)$. Supplementary Table S2 provides information on the post-procedural changes in BP by center. The individual responses to RDN were highly variable (Figure 2), with increases in office and 24-h systolic BPs in 25 (22.9\%) and 38 (34.9\%) patients (Table 3). Office or 24-h systolic BP was at goal under antihypertensive treatment in 25 (22.9\%) and $16(14.7 \%)$ of 109 patients, respectively; in RDN patients with an office systolic BP of at least $160 \mathrm{~mm} \mathrm{Hg}$, these numbers were $12(16.2 \%)$ and 8 (10.8\%).

The procedural complications encompassed hematomata at the puncture site $(n=8)$, progression of a nonsignificant $(<30 \%)$ renal artery stenosis $(n=3)$, transient decline in renal function $(n=1)$ and orthostatic hypotension in medication-intolerant and therefore initially untreated patients $(n=2)$.

\section{Adjusted analyses of the responses to RDN}

In analyses adjusted for the baseline BP as fixed effect and center as random effect, the systolic/diastolic responses $(P \leqslant 0.014)$ were 
Table 2. Baseline values and 6-month Changes in blood pressure in 109 patients

\begin{tabular}{|c|c|c|}
\hline Variable & Systolic pressure & Diastolic pressure \\
\hline \multicolumn{3}{|c|}{ Office, $\mathrm{mm} \mathrm{Hg}$} \\
\hline $\mathrm{BL}$ & $174.5 \pm 25.7$ & $98.0 \pm 18.6$ \\
\hline$\Delta \mathrm{u}$ & $-17.6(-22.0$ to -13.1$) \pm$ & $-7.1(-9.8$ to -4.5$) \ddagger$ \\
\hline$\Delta \mathrm{a}$ & $-14.2(-17.7$ to -10.6$) \ddagger$ & $-6.5(-8.8$ to -4.2$) \ddagger$ \\
\hline \multicolumn{3}{|c|}{ 24-h, $\mathrm{mm} \mathrm{Hg}$} \\
\hline $\mathrm{BL}$ & $156.7 \pm 17.4$ & $91.5 \pm 14.2$ \\
\hline$\Delta \mathrm{u}$ & $-5.9(-9.0$ to -2.8$) \ddagger$ & $-3.5(-5.5$ to -1.5$) \ddagger$ \\
\hline$\Delta \mathrm{a}$ & $-5.2(-7.9$ to -2.6$) \ddagger$ & $-3.1(-4.7$ to -1.4$) \ddagger$ \\
\hline \multicolumn{3}{|c|}{ Daytime, $\mathrm{mm} \mathrm{Hg}$} \\
\hline $\mathrm{BL}$ & $160.8 \pm 18.0$ & $94.9 \pm 15.3$ \\
\hline$\Delta \mathrm{u}$ & $-6.2(-9.5$ to -2.9$) \dagger$ & $-3.4(-5.5$ to -1.4$) \ddagger$ \\
\hline$\Delta \mathrm{a}$ & $-5.6(-8.3$ to -2.8$) \ddagger$ & $-3.3(-5.1$ to -1.5$) \ddagger$ \\
\hline \multicolumn{3}{|c|}{ Nighttime, $\mathrm{mm} \mathrm{Hg}$} \\
\hline $\mathrm{BL}$ & $147.0 \pm 20.8$ & $83.5 \pm 15.1$ \\
\hline$\Delta \mathrm{u}$ & $-4.4(-7.9 \text { to }-1.0)^{*}$ & $-2.5(-4.8 \text { to }-0.2)^{*}$ \\
\hline$\Delta \mathrm{a}$ & $-4.9(-7.7$ to -2.1$) \ddagger$ & $-2.3(-4.1 \text { to }-0.5)^{*}$ \\
\hline \multicolumn{3}{|c|}{ Office minus $24-h, m m ~ H g$} \\
\hline & $18.2 \pm 22.5$ & $6.7 \pm 13.4$ \\
\hline$\Delta \mathrm{u}$ & $-12.0(-16.4$ to -7.7$) \ddagger$ & $-3.7(-6.2$ to -1.3$) \dagger$ \\
\hline$\Delta \mathrm{a}$ & $-7.7(-10.7$ to -4.6$) \ddagger$ & $-2.6(-4.6$ to -0.7$) \dagger$ \\
\hline \multicolumn{3}{|c|}{ Office minus daytime, $\mathrm{mm} \mathrm{Hg}$} \\
\hline $\mathrm{BL}$ & $14.0 \pm 22.6$ & $3.3 \pm 14.1$ \\
\hline$\Delta \mathrm{u}$ & $-11.8(-16.2$ to -7.4$) \ddagger$ & $-3.7(-6.2$ to -1.3$) \dagger$ \\
\hline$\Delta \mathrm{a}$ & $-8.4(-11.7$ to -5.1$) \ddagger$ & $-2.6(-4.6 \text { to }-0.6)^{*}$ \\
\hline \multicolumn{3}{|c|}{$\begin{array}{l}\mathrm{BL}, \Delta \mathrm{u} \text { and } \Delta \mathrm{a} \text { respectively indicate baseline value, unadjusted change } \\
\text { (follow-up minus baseline), and change estimates derived from mixed } \\
\text { models, while adjusting for baseline as fixed effect and center as random } \\
\text { effect. Baseline values are mean } \pm \mathrm{s} \text {.d. Changes are crude or adjusted } \\
\text { means with } 95 \% \text { confidence interval. Office minus } 24-\mathrm{h} \text { or daytime blood } \\
\text { pressure is a measure for the white-coat effect. Significance of the changes: } \\
{ }^{*} P \leqslant 0.05 ; \dagger P \leqslant 0.01 ; \ddagger P \leqslant 0.001 \text {. }\end{array}$} \\
\hline
\end{tabular}

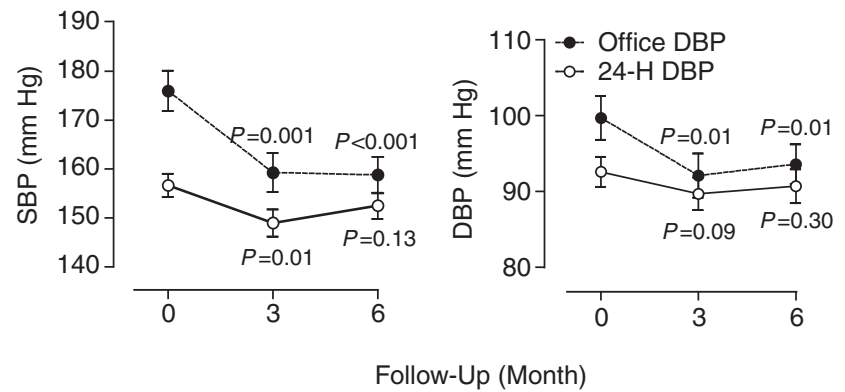

Figure 1. The office and 24-h ambulatory BP values at baseline and at 3 and 6 months after RDN in 47 patients. SBP and DBP indicate systolic and diastolic $B P$, respectively. $P$-values denote the significance compared with baseline in unadjusted analyses.

14.2/6.5 $\mathrm{mm} \mathrm{Hg}$ for office $B P$, and $5.2 / 3.1 \mathrm{~mm} \mathrm{Hg}, 5.6 / 3.3 \mathrm{~mm} \mathrm{Hg}$ and $4.9 / 2.3 \mathrm{~mm} \mathrm{Hg}$ for the $24-\mathrm{h}$, daytime and nighttime BPs, respectively (Table 2 ). Adjusted estimates for the decreases in the systolic/diastolic white-coat effect derived from 24-h or daytime recordings were $7.7 / 2.6 \mathrm{~mm} \mathrm{Hg}$ and $8.4 / 2.6 \mathrm{~mm} \mathrm{Hg}$, respectively $(P \leqslant 0.011)$. Multivariable-adjusted analyses of office and 24-h systolic BP level achieved 6 months after RDN revealed that higher baseline values were associated with greater fall in BP $(P<0.001$; Supplementary Table S3). Previous cardiovascular disease predicted a $9.8 \mathrm{~mm} \mathrm{Hg}$ greater decline in office systolic BP $(P=0.048)$ and a $20-\mu \mathrm{molI}^{-1}$ higher serum creatinine concentration at
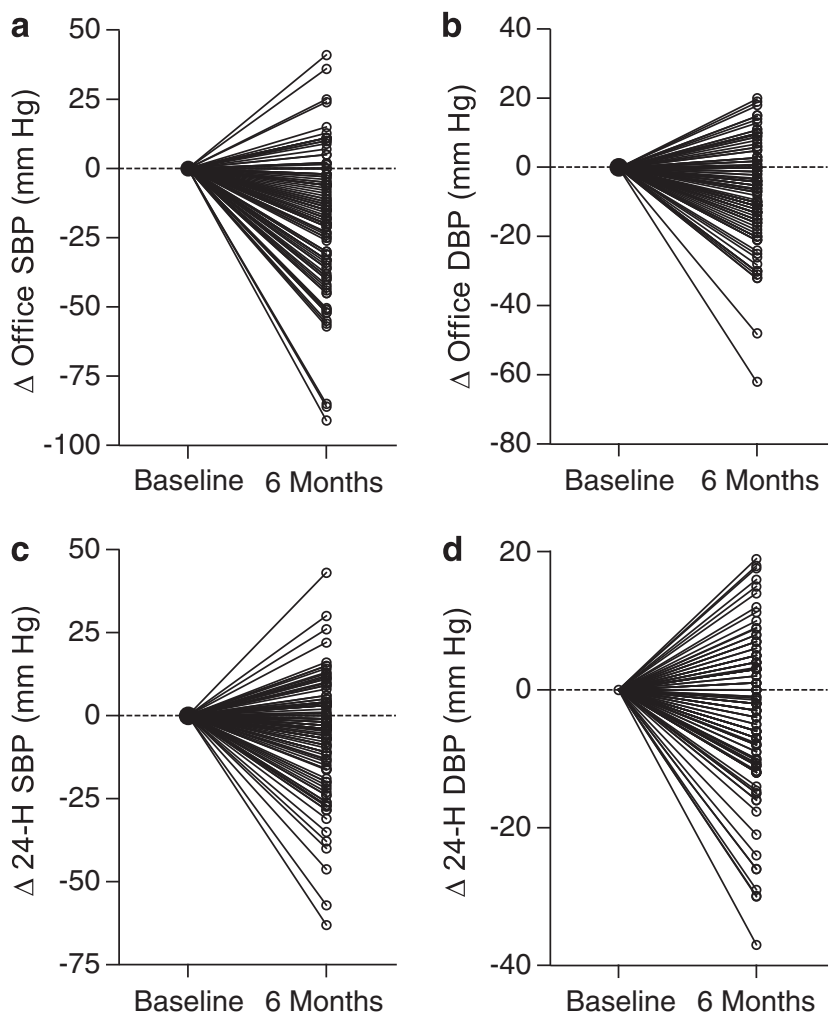

Figure 2. Individual responses of systolic (a, c) and diastolic (b, d) BP on office $(\mathbf{a}, \mathbf{b})$ and 24-h ambulatory (c, d) measurement in 109 patients undergoing RDN.

baseline predicted a 2.8- $\mathrm{mm} \mathrm{Hg}$ lesser decrease in 24-h systolic BP $(P=0.048)$.

In multivariable-adjusted categorical analyses of the systolic BP responses (Table 4), baseline levels of BP and serum creatinine were the predominant predictors (Table 4). Higher baseline BP was associated with lower probability of reaching BP control (odds ratio (OR) for office and 24-h systolic $B P, 0.78$ and $0.49 ; P \leqslant 0.039$ ), higher probability of experiencing a decrease in systolic BP by $10 \mathrm{~mm} \mathrm{Hg}$ or more (OR, 1.36 and $1.31 ; P \leqslant 0.059)$ and lower probability of experiencing no decrease in office systolic BP (OR, $0.71 ; P \leqslant 0.013)$. Higher serum creatinine concentration was associated with lower probability of systolic BP control on 24ambulatory monitoring (OR, $0.53 ; P=0.082)$ or improvement of systolic BP on office or 24-h ambulatory measurement (OR, 0.61 and $0.60 ; P \leqslant 0.050)$ and higher probability of experiencing no decrease in systolic BP (OR, 1.80 and $1.66 ; P \leqslant 0.016)$.

\section{Comparison with SYMPLICITY HTN-2 Patients}

After exclusion of our current patients with a baseline systolic BP on office measurement of $<160 \mathrm{~mm} \mathrm{Hg}$ to match the SYMPLICITY recruitment criteria, the proportion of our current patients experiencing no decrease or an improvement was of similar magnitude as in the SYMPLICITY HTN-2 report, ${ }^{3}$ whereas control was reached in fewer of our current patients (Figure 3).

\section{Comparison with Syst-Eur patients}

At baseline, systolic BP on office and 24-h, daytime and nighttime measurement and the serum creatinine concentration were similar $(P \geqslant 0.12)$ among RDN and Syst-Eur patients (Supplementary Table S4). Compared with our current RDN patients, at 6 months, office systolic BP $(-17.6 \mathrm{vs}-7.7 \mathrm{~mm} \mathrm{Hg})$ and the white-coat effect derived either from $24-\mathrm{h}$ ( -12.0 vs 
$-5.7 \mathrm{~mm} \mathrm{Hg})$ or daytime $(-11.8 \mathrm{vs}-5.7 \mathrm{~mm} \mathrm{Hg})$ BP monitoring decreased less $(P \leqslant 0.042)$ in 73 Syst-Eur patients randomized to placebo, whereas the changes in the ambulatory BP levels were similar $(P \geqslant 0.13)$. Among 79 Syst-Eur patients randomized to active treatment, the decreases in the 24-h and nighttime systolic BP were larger than in RDN patients $(P \leqslant 0.013)$, whereas changes in daytime systolic BP and in the white-coat effect were similar $(P \geqslant 0.22)$. The aforementioned findings were consistent (Supplementary Table S5) in mixed models adjusted for baseline, sex, age, body mass index, diabetes mellitus and a history of cardiovascular disease (fixed effects) and study (RDN vs Syst-Eur modeled as random effect).

Table 3. Status of systolic blood pressure at 6 months

\begin{tabular}{lcccc}
\hline Variable & \multicolumn{5}{c}{ Office systolic pressure at baseline $(\mathrm{mm} \mathrm{Hg})$} \\
\cline { 2 - 5 } & $<160$ & $160-179$ & $\geqslant 180$ & $\begin{array}{c}\text { Whole } \\
\text { range }\end{array}$ \\
& & & & 109 \\
\hline $\begin{array}{l}\text { Number of } \\
\text { patients }\end{array}$ & 35 & 33 & 41 & \\
$\begin{array}{l}\text { Office blood pressure } \\
\quad \text { Normalization }\end{array}$ & $13(37.1)$ & $8(24.2)$ & $4(9.8)^{*}$ & $25(22.9)$ \\
$\begin{array}{l}\text { Improved } \\
\text { No decrease }\end{array}$ & $12(34.3)$ & $21(63.6) \dagger$ & $32(78.0)$ & $65(59.6)$ \\
& $14(40.0)$ & $7(21.2)$ & $4(9.8)$ & $25(22.9)$ \\
$\begin{array}{l}\text { 24- } h \text { blood pressure } \\
\quad \text { Normalization }\end{array}$ & $8(22.9)$ & $6(18.2)$ & $2(4.9)^{*}$ & $16(14.7)$ \\
Improved & $13(37.1)$ & $11(33.3)$ & $10(24.4)$ & $34(31.2)$ \\
$\quad$ No decrease & $13(37.1)$ & $13(39.4)$ & $12(29.3)$ & $38(34.9)$ \\
\hline
\end{tabular}

Values are number of patients (\%). Reaching normal systolic blood pressure was achieving levels $<140 \mathrm{~mm} \mathrm{Hg}$ or $<130 \mathrm{~mm} \mathrm{Hg}$ on office or 24-h ambulatory measurement, respectively. Improvement was a decrease in the office or 24 -h systolic pressure by $\geqslant 10 \mathrm{~mm} \mathrm{Hg}$. No decrease was a systolic pressure at 6 months equal to or higher than the baseline value. Numbers do not add up, because of overlap between categories of achieved blood pressure. Significance of the difference with the left adjacent subgroup: ${ }^{*} 0.07 \leqslant P \leqslant 0.09 ; \uparrow P=0.01$

\section{DISCUSSION}

This report is the first subject-level meta-analysis of the 6-month responses of both office and ambulatory BP to RDN in carefully selected patients in whom secondary hypertension was excluded and who had resistant hypertension confirmed by ambulatory monitoring. The key findings were that the BP responses to RDN were: (i) highly variable in individual patients; (ii) on average considerably smaller on ambulatory than office measurement (iii) and smaller than reported in previous studies. ${ }^{2-4}$ The systolic BP changes averaged -17.6 on office measurement and $-5.9 \mathrm{~mm} \mathrm{Hg}$ on 24-h ambulatory monitoring, but the individual responses ranged from -91 to $+41 \mathrm{~mm} \mathrm{Hg}$ and from -63 to $+43 \mathrm{~mm} \mathrm{Hg}$, respectively. The decrease in BP was already achieved at 3 months with no further reduction at 6 months. Office or 24-h systolic BP was at goal under antihypertensive treatment in $22.9 \%$ and $14.7 \%$ of 109 patients, respectively.

After exclusion of patients with a baseline systolic BP on office measurement of $<160 \mathrm{~mm} \mathrm{Hg}$, the proportion of our current RDN patients experiencing no decrease or an improvement was of similar magnitude as in the SYMPLICITY HTN-2 report, ${ }^{3}$ whereas control was reached in fewer of our patients. In the SYMPLICITY HTN-2 study, ${ }^{3}$ the 24-h systolic BP decreased by $11 \pm 15 \mathrm{~mm} \mathrm{Hg}$ $(P=0.006)$ in 20 RDN patients and did not change in 25 controls $(-3 \pm 19 \mathrm{~mm} \mathrm{Hg} ; \quad P=0.51)$, resulting in a unreported nonsignificant between-group difference of $8 \mathrm{~mm} \mathrm{Hg}$, as recalculated from the published data $(t=1.61 ; P=0.11)$. Remarkably, the SYMPLICITY HTN-2 report also did not include the baseline ambulatory BP in Table $1 .^{3}$ Our current study reports on the largest database of ambulatory BP measurements following RDN.

Our results revealed smaller reductions in the office and ambulatory BP than those observed in the SYMPLICITY HTN-2 trial $^{3}$ or in a subsequent meta-analysis, ${ }^{20}$ even though compared with these other studies 3,20 our patients had similar office BP, treatment score, renal function and baseline characteristics, being mainly white and obese. Davis et $a l^{20}$ stated that they did a metaanalysis of summary statistics extracted from two randomized controlled trials, one observational study with a control group and nine observational studies without a control group. In controlled studies, the reduction in office systolic BP at 6 months was -28.9

Table 4. Baseline predictors of the 6-month responses of office and 24-h systolic blood pressures to renal denervation in 109 patients

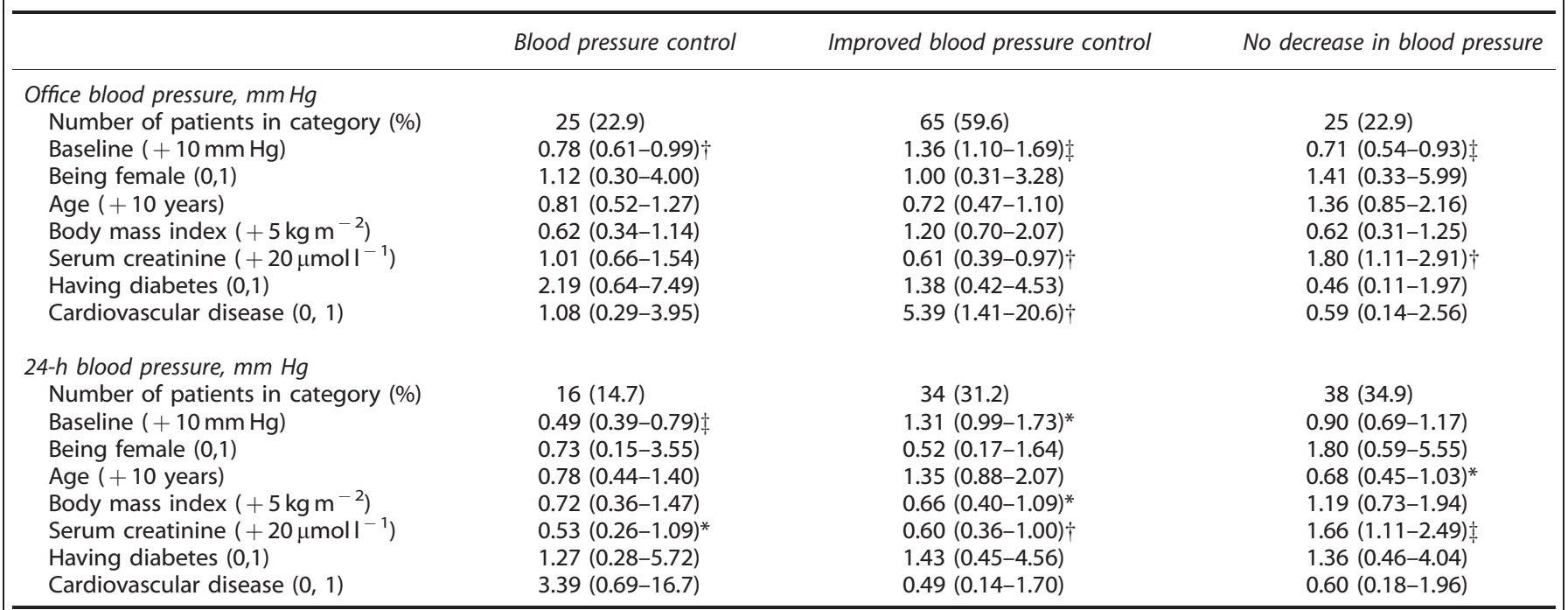

Values are independent odds ratios with $95 \%$ confidence interval. All estimates were adjusted for the baseline systolic blood pressure and for all other predictors considered (see Table 3). Reaching control was achieving a systolic pressure $<140 \mathrm{~mm} \mathrm{Hg}$ or $<130 \mathrm{~mm} \mathrm{Hg}$ on office or $24-\mathrm{h}$ ambulatory measurement, respectively. Reaching improved control was a decrease in the office or 24 -h systolic pressure by $\geqslant 10 \mathrm{~mm} \mathrm{Hg}$. No decrease was a systolic pressure at 6 months equal to or higher than the baseline value. Significance of the odds ratios: ${ }^{*} P \leqslant 0.10 ; \dagger P \leqslant 0.05 ; \uparrow P \leqslant 0.01$. 


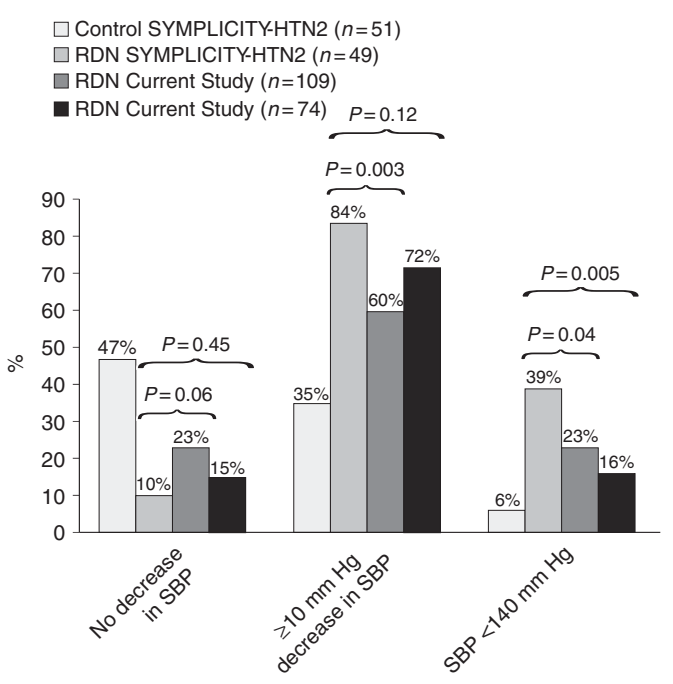

Figure 3. Proportion of SYMPLICITY-HTN2 patients in the control $(n=51)$ and RDN $(n=49)$ group and proportion of patients in the current study that at 6 months had no decrease in the office systolic $\mathrm{BP}, \mathrm{a} 10-\mathrm{mm} \mathrm{Hg}$ or greater decrease, or had a systolic BP of $<140 \mathrm{~mm} \mathrm{Hg}$. For the current study, proportions are given for all patients $(n=109)$ as well as for those who at baseline had an office systolic BP of $160 \mathrm{~mm} \mathrm{Hg}$ or more $(n=74)$. $P$-values are for the comparison between the SYMPLICITY HTN-2 RDN group and the current patients.

compared with medically treated patients. ${ }^{20}$ In uncontrolled studies, there was a reduction by $-25.0 \mathrm{~mm} \mathrm{Hg}{ }^{20}$ The high variability of the individual $B P$ responses to RDN might explain why in some studies office $\mathrm{BP}^{21}$ ambulatory $\mathrm{BP}^{22-24}$ or both ${ }^{25}$ did not decrease. Other reasons that might explain at least in part differences in the estimates of the responses to RDN are: (i) a stringent selection of patients with truly resistant hypertension confirmed by ambulatory BP monitoring, in whom secondary hypertension was excluded by an extensive workup and in whom treatment had been optimized ${ }^{26}$ and (ii) the high quality of the office and ambulatory BP measurements at the top European centers that participated in the current study.

In our current study, the average decrease in the 24-h systolic BP was only one-third of the reduction in the office systolic BP and much smaller than expected based on the literature. ${ }^{27-30}$ It exceeded the placebo effect observed in the Syst-Eur trial by $<4 \mathrm{mmHg}$ (see online Supplementary Data). As previously reported in 244 Syst-Eur patients, ${ }^{27}$ the ratio of the systolic BP fall on daytime ambulatory to office measurement was $0.59(-9.3$ vs $-16.6 \mathrm{~mm} \mathrm{Hg}$ ). In the Ambulatory Blood Pressure Monitoring and Treatment of Hypertension trial, ${ }^{28}$ this ratio was 0.64 ( -14.3 vs $-22.4 \mathrm{~mm} \mathrm{Hg}$ ). In the Treatment of Hypertension Based on Home or Office Blood Pressure trial, ${ }^{29}$ the systolic home-to-office ratio was $0.73(-13.5$ vs $-18.6 \mathrm{~mm} \mathrm{Hg})$. In the current RDN patients, this ratio was only $0.35(-6.2$ vs $-17.6 \mathrm{~mm} \mathrm{Hg})$. The discrepancy between office and ambulatory BP in response to RDN and the small effect of RDN on 24-h systolic BP remain a matter of particular concern, as the $24-h^{31,32}$ daytime ${ }^{31-33}$ and nighttime ${ }^{31,32,34}$ systolic $B P$ values outperform office systolic BP in predicting fatal and nonfatal and overall and cause-specific cardiovascular complications. Consequently, whether RDN would translate into a reduction of cardiovascular events - the ultimate goal of any blood-pressure lowering intervention-remains to be proven.

The hypothesis that the sympatholytic effects mediated by RDN may have more pronounced effects on office than on ambulatory $\mathrm{BP}$ by inhibition of the white-coat effect ${ }^{35}$ remains currently unproven. A more likely explanation is that a substantial proportion of the benefits attributed to RDN may reflect placebo effects and/or regression-to-the-mean. In keeping with the SYMPLICITY data, ${ }^{3,4}$ higher systolic BP at baseline was associated with a higher probability of experiencing an improvement in control and lower probability of experiencing an increase in BP. This observation identifies regression-to-the-mean as an important confounder contributing to the BP decrease in RDN studies. The online Data Supplement highlights that whatever lowers office systolic BP-RDN, placebo or antihypertensive drug treatment-by definition, such intervention must decrease the white-coat effect. Attenuation of the white-coat effect was larger on antihypertensive drug treatment and RDN compared with placebo.

The present study must be interpreted within the contest of potential limitations and strengths. First, the centers contributing patients applied different recruitment criteria. However, introducing center as a random effect in the continuous and categorical analyses of the BP responses to RDN did not materially change our results. Second, in our study, RDN relied for $90 \%$ on the use of the Ardian-Medtronic system so that our findings cannot be extrapolated to other devices with a different design. However, Davis et al. ${ }^{20}$ did not find any differences between catheter systems. Third, although we have shown creatinine to be a significant predictor of less effect, the mean eGFR in our patients was within the normal range. Fourth, our current analysis does not allow explaining the mechanisms underlying the BP responses to RDN. As in the SYMPLICITY-HTN2 study, ${ }^{3}$ none of the conditions associated with increased sympathetic tone, such as renal impairment or diabetes mellitus, were associated with a larger decline in BP in response to RDN. Although our current study is the largest published so far that uses ambulatory BP monitoring in RDN patients, lack of statistical power might still be an issue. Nevertheless, one should consider other possibilities: (i) sympathetic nervous tone might be less important than expected in resistant hypertension ${ }^{36}$ or (ii) the proportion of fibers ablated using the first-generation Ardian-Medtronic catheter is insufficient, a marker of efficacious nervous ablation still being unavailable for clinical use in humans. Fifth, the comparisons with the SYMPLICITY HTN-2 trial $^{3}$ and with Syst-Eur ${ }^{9}$ were retrospective. Comparisons with SYMPLICITY HTN-2 remained unadjusted, whereas those with Syst-Eur were multivariableadjusted for differences in the baseline patient characteristics (fixed effects) and for study (random effect). Compared with RDN patients, Syst-Eur patients were older and leaner, had lower eGFR and less often suffered from diabetes mellitus or coronary heart disease (see Data Supplement). However, within the context of this limitation, the comparison of the effects of RDN in resistant hypertension with that of antihypertensive drug treatment in another form of difficult-to-control hypertension-isolated systolic hypertension-is both relevant and hypothesis-generating.

Finally, not observational studies, but only sufficiently powered randomized clinical trials can address the question whether RDN is effective and safe and whether its effects differ in patients with normal as compared with impaired renal function. While the SYMPLICITY HTN-3 randomized controlled trial (NCT01418261) ${ }^{37}$ is expected to be completed within the next few months, it is not sure that its results can be readily extrapolated to European countries. Despite the superiority of ambulatory over office BP to predict prognosis, ${ }^{31-34}$ particularly in the context of resistant hypertension, ${ }^{32}$ the primary endpoint of this trial ${ }^{37}$ is still the baseline-adjusted between-group difference in office systolic BP. Several smaller European trials ongoing in France (NCT01570777, NCT01588795) and Norway (NCT01673516) will also report by the end of this year or next year. These studies and others being planned include ancillary studies on cardiac and arterial structure and function that will achieve a high degree of standardization within the networked ENCOReD centers. 
Research priorities for RDN are the unequivocal demonstration of increased sympathetic nervous activity in patients with resistant hypertension, proof of effective sympathetic inhibition by RDN, for instance by stimulating the renal nerves before and after RDN, ${ }^{38}$ and the identification of reliable predictors of BP response to RDN. From a clinical point of view, only a small minority of treatmentresistant patients qualifies for RDN. . $^{2,39}$ RDN is an invasive procedure that is not devoid of risk ${ }^{40-42}$ and comes at a high cost. The wide-spread deployment of RDN in routine clinical practice, in particular on referral to interventionists without involvement of a multidisciplinary team including a hypertension specialist$^{26}$ does not meet the ethical precept in medicine: 'primum non nocere' (primum non nocere ('first, do no harm') is one of the principal precepts of medical ethics. Another way to state it is that, 'given an existing problem, it may be better not to do something, or even to do nothing, than to risk causing more harm than good'. It reminds physicians that they must consider the possible harm that any intervention might do.). RDN should remain the last resort in patients in whom all other means to control BP failed and given our current findings should be used with restraint in patients with renal impairment, irrespective of whether the cause is a diseased kidney or prerenal, such as in heart failure.

\section{What is known about topic}

- The SYMPLICITY studies demonstrated that catheter-based endovascular sympathetic renal denervation (RDN) by means of low-frequency energy is feasible.

- In the SYMPLICITY studies, RDN entailed a $25-30 \mathrm{~mm} \mathrm{Hg}$ decrease in office systolic blood pressure (BP), $84 \%$ of patients achieving a decrease in office systolic BP of $\geqslant 10 \mathrm{~mm} \mathrm{Hg}$; the post-procedural changes in the ambulatory BP were reported in few studies and did not always reach statistical significance.

What this study adds

- This report is the first published subject-level meta-analysis of the 6month responses of office and ambulatory BP to RDN.

- The BP response to RDN was highly variable among individual patients and on average larger on office than daytime ambulatory BP measurement ( -17.6 vs $-6.2 \mathrm{~mm} \mathrm{Hg}$ ).

- In RDN patients, lower initial BP and higher serum creatinine predicted a smaller BP response.

- The mean BP response to RDN is less than previously reported and includes placebo effects and regression to the mean.

\section{CONFLICT OF INTEREST}

The authors declare no conflict of interest.

\section{ACKNOWLEDGEMENTS}

The European Union (grants IC15-CT98-0329-EPOGH, LSHM-CT-2006-037093-InGenious HyperCare, HEALTH-2007-2.1.1-2-HyperGenes, HEALTH-2011.2.4.2-2-EU-MASCARA, HEALTH-F7-305507 HOMAGE and the European Research Council Advanced Researcher Grant-2011-294713-EPLORE) and the Ministry of the Flemish Community, Brussels, Belgium (grants G.0734.09, G.0881.13 and G.088013N) supported the Studies Coordinating Centre, Leuven, Belgium. None of the authors received financial support for the current analysis.

\section{REFERENCES}

1 Staessen JA, Kuznetsova T, Stolarz K. Hypertension prevalence and stroke mortality across populations. JAMA 2003; 289: 2420-2422.

2 Krum H, Schlaich M, Whitbourn R, Sobotka PA, Sadowski J, Bartus K et al. Catheterbased renal sympathetic denervation for resistant hypertension: a multicentre safety and proof-of-principle cohort study. Lancet 2009; 373: 1275-1281.
3 Esler MD, Krum H, Sobotka PA, Schlaich MP, Schmieder RE, Böhm M. Symplicity HTN-2 Investigators. Renal sympathetic denervation in patients with treatmentresistant hypertension (The Symplicity HTN-2 Trial): a randomised controlled trial. Lancet 2010; 376: 1903-1909.

4 Symplicity HTN-1. Investigators. Catheter-based renal sympathetic denervation for resistant hypertension. Durability of blood pressure reduction out to 24 months. Hypertension 2011; 57: 911-917.

5 Azizi M, Steichen O, Frank M, Bobrie G, Plouin PF, Sapoval M. Catheter-based radiofrequency renal ablation in patients with resistant hypertension. Eur J Vasc Endovasc Surg 2012; 43: 293-299.

6 Persu A, Renkin J, Thijs L, Staessen JA. Renal denervation - Ultima ratio or standard in treatment-resistant hypertension. Hypertension 2012; 60: 596-606.

7 Persu A, Renkin J, Asayama K, O'Brien E, Staessen JA. Renal denervation in treatment-resistant hypertension: the need for restraint and more and better evidence. Expert Rev Cardiovasc Ther 2013; 11: 739-749.

8 Stamatakis E, Weiler R, loannidis JPA. Undue industry influences that distort healtcare research, strategy, expenditure and practice: a review. Eur J Clin Invest 2013; 43: 469-475.

9 Staessen JA, Fagard R, Thijs L, Celis H, Arabidze GG, Birkenhäger WH et al. Randomised double-blind comparison of placebo and active treatment for older patients with isolated systolic hypertension. Lancet 1997; 350: 757-764.

10 Staessen J, Amery A, Fagard R. Editorial review. Isolated systolic hypertension in the elderly. J Hypertens 1990; 8: 393-405.

11 Pisoni R, Ahmed Ml, Calhoun DA. Characterization and treatment of resitant hypertension. Curr Cardiol Rep 2009; 11: 407-413.

12 Schmieder RE, Redon J, Grassi G, Kjeldsen JE, Mancia G, Narkiewicz K et al. ESH position paper: renal denervation - an interventional therapy of resistant hypertension. J Hypertens 2012; 30: 387-841.

13 Levey AS, Bosch JP, Lewis JB, Greene T, Rogers N, Roth D et al. A more accurate method to estimate glomerular filtration rate from serum creatinine: a new prediction equation. Ann Intern Med 1999; 130: 461-470.

14 Pathak A, Girerd X, Azizi M, Benamer $\mathrm{H}$, Halimi JM, Lantelme $\mathrm{P}$ et al. Expert consensus: Renal denervation for the treatment of hypertension. Diagn Interv Imaging 2012; 93: 386-394.

15 Staessen JA, Thijs L, Clement D, Davidson C, Fagard R, Lehtonen A et al. Ambulatory pressure decreases in long-term placebo treatment in older patients with isolated systolic hypertension. J Hypertens 1994; 12: 1035-1039.

16 O'Brien E, Mee F, Tan S, Atkins N, O'Malley K. Training and assessment of observers for blood pressure measurement in hypertension research. J Hum Hypertens 1991; 5: 7-10.

17 O'Brien E, Mee F, Atkins N, O'Malley K. Technical aspects of ambulatory blood pressure monitoring in the elderly. Cardiol Elderly 1993; 1: 464-469.

18 O'Brien E, Asmar R, Beilin L, Imai Y, Mancia G, Mengden T et al. Practice guidelines of the European Society of Hypertension for clinic, ambulatory and self blood pressure measurement. J Hypertens 2005; 23: 697-701.

19 Fagard R, Brguljan J, Thijs L, Staessen J. Prediction of the actual awake and asleep blood pressures by various methods of $24 \mathrm{~h}$ pressure analysis. J Hypertens 1996; 14: 557-563.

20 Davis MI, Filion KB, Zhang D, Eisenberg MJ, Afilalo J, Schiffrin EL et al. Effectiveness of renal denervation therapy for resistant hypertension: a systematic reveiw and meta-analysis. J Am Coll Cardiol 2013; 62: 231-241.

21 Brinkmann J, Heusser K, Schmidt BM, Menne J, Klein G, Bauersachs J et al. Catheter-based renal nerve ablation and centrally generated sympathetic activity in difficult-to-control hypertensive patients: prospective case series. Hypertension 2012; 60: 1485-1490.

22 Witkowski A, Prejbisz A, Florczak E, Kadziela J, Sliwinsky P, Bielen P et al. Effects of renal sympathetic denervation on blood pressure, sleep apnea course, and glycemic control in patients with resistant hypertension and sleep apnea. Hypertension 2011; 58: 559-565.

23 Hering D, Mahfoud F, Walton AS, Krum H, Lambert GW, Lambert EA et al. Renal denervation in moderate to severe CKD. J Am Soc Nephrol 2012; 23: 1250-1257.

24 Zuern CS, Rizas KD, Eick C, Stoleriu C, Bunk L, Barthel P et al. Effects of renal sympathetic denervation on 24-hour blood pressure variability. Front Physiol 2012; 3: 1-8.

25 Fadl-Elmula FE, Hoffmann P, Fossum E, Brekke M, Gjønnæss E, Hjørnholm U et al. Renal sympathetic denervation in patients with treatment resistant hypertension following witnessed intake of medication prior to qualifying ambulatory blood pressure. Hypertension 2013; 62: 526-532.

26 Verloop WL, Vink EE, Voskuil M, Vonken EJ, Rookmaker MB, Bots ML et al. Eligibility for percutaneous renal denervation: the importance of a systematic screening. J Hypertens 2013; 31: 1662-1668.

27 Staessen JA, Thijs L, Bijttebier G, Clement D, O'Brien ET, Palatini P et al. Determining the trough-to-peak ratio in parallel-group trials. Hypertension 1997; 29: 659-667.

28 Staessen JA, Byttebier G, Buntinx F, Celis H, O'Brien ET, Fagard R et al. Antihypertensive treatment based on conventional or ambulatory blood pressure measurement. A randomized controlled trial. JAMA 1997; 278: 1065-1072. 
29 Staessen JA, Den Hond E, Celis H, Fagard R, Keary L, Vandenhoven G et al. Antihypertensive treatment based on blood pressure measurement at home or in the physician's office. A randomized controlled trial. JAMA 2004; 291: 955-964.

30 Mancia G, Parati G. Office compared with ambulatory blood pressure in assessing response to antihypertensive treatment: a meta-analysis. J Hypertens 2004; 22: 435-445.

31 Staessen JA, Thijs L, Fagard R, O'Brien ET, Clement D, de Leeuw PW et al. Predicting cardiovascular risk using conventional and ambulatory blood pressure in older patients with systolic hypertension. JAMA 1999; 282: 539-546.

32 Salles GF, Cardoso CR, Muxfeldt ES. Prognostic influence of office and ambulatory blood pressures in resistant hypertension. Arch Intern Med 2008; 168: 2340-2346.

33 Hansen TW, Kikuya M, Thijs L, Björklund-Bodegård K, Kuznetsova T, Ohkubo T et al. Prognostic superiority of daytime ambulatory over conventional blood pressure in four populatios: a meta-analasis of 7030 individuals. J Hypertens 2007; 25: 1554-1564.

34 Boggia J, Thijs L, Hansen TW, Li Y, Kikuya M, Björklund-Bodegård K et al. Ambulatory blood pressure monitoring in 9357 subjects from 11 populations highlights missed opportunities for cardiovascular prevention in women. Hypertension 2011 57: $397-405$.

35 Doumas M, Anyfanti P, Bakris G. Should ambulatory blood pressure monitoring be mandatory for future studies in resistant hypertension: a perspective. $J$ Hypertens 2012; 30: 874-876

36 Tsioufis C, Kordalis A, Flessas D, Anastasopoulos I, Tsiachris D, Papademetriou V et al. Pathophysiology of resistant hypertension: role of the sympathetic nervous system. Int J Hypertens 2011; 20: 642416.
37 Kandzari DE, Bhatt DL, Sobotka PA, O'Neill WW, Esler M, Flack JM et al. Catheterbased renal denervation for resistant hypertension: rational and design of the SYMPLICITY HTN-3 trial. Clin Cardiol 2012; 35: 528-535.

38 Chinushi M, Izumi D, lijima K, Suzuki K, Furushima H, Saitoh O et al. Blood pressure and autonomic responses to electrical stimulation of the renal arterial nerves before and after ablation of the renal artery. Hypertension 2013; 61 : 450-456.

39 Savard S, Frank M, Bobrie G, Plouin PF, Sapoval M, Azizi M. Eligibility for renal denervation in patients with resistant hypertension: when enthusiasm meets reality in real-life patients. J Am Coll Cardiol 2012; 60: 2422-2424.

40 Vonend O, Antoch G, Rump LC, Blondin D. Secondary rise in blood pressure after renal denervation. Lancet 2012; 380: 778.

41 Kaltenbach B, Id D, Franke JC, Sievert H, Hennersdorf M, Maier J et al. Renal artery stenosis after renal sympathetic denervation. J Am Coll Cardiol 2012; 60: 2694-2695.

42 Templin C, Jaguszewski M, Ghadri JR, Sudano I, Gaehwiler R, Hellermann JP et al. Vascular lesions induced by renal nerve ablation as assessed by optical coherence tomography: pre-and post-procedural comparison with the Simplicity catheter system and the EnligHTN ${ }^{\mathrm{TM}}$ multi-electrode renal denervation catheter. Eur Heart $J$ 2013; 34: 2141-2148.

(i) $\Theta$ This work is licensed under a Creative Commons AttributionNonCommercial-NoDerivs 3.0 Unported License. To view a copy of this license, visit http://creativecommons.org/licenses/by-nc-nd/3.0/

Supplementary Information accompanies this paper on the Journal of Human Hypertension website (http://www.nature.com/jhh) 